\title{
Comment on Early versus delayed mobilization for in-hospital mortality and health-related quality of life among critically ill patients: a systematic review and meta-analysis (Okada et al., Journal of Intensive Care 2019)
}

\author{
K. Friedrich Kuhn (1) and Stefan J. Schaller ${ }^{*}$ (D)
}

\begin{abstract}
Critical comment on the review by Okada et al. on the effect of early versus delayed mobilization because of their definition of early mobilization as mobilization within a week of ICU admission in contrast to current evidence.
\end{abstract}

Keywords: ICU, Critical illness, Early mobilization

\section{Comment}

In their systematic review and meta-analysis, Okada et al. investigate the impact of early versus delayed mobilization for in-hospital mortality and health-related quality of life among critically ill patients, including 11 studies in their meta-analysis [1]. They compared randomized controlled trials (RCTs) starting mobilization within 1 week of ICU admission to those initiating mobilization later than 1 week.

Aware that there is no uniform definition of "early mobilization" in the ICU yet, to use 1 week as cut-off point seems unreasonable for various reasons. So far, only studies starting early mobilization within $72 \mathrm{~h}$ have been able to improve patient outcomes, as summarized in published narrative reviews [2] with adoption in practice guidelines [3]. Schweickert et al. applied physical therapy and interruption of sedation within $72 \mathrm{~h}$ of ICU admission causing higher independent functionality at hospital discharge, shorter duration of delirium, and more ventilator-free days [4]. In another single-center

\footnotetext{
* Correspondence: stefan.schaller@charite.de

Charité - Universitätsmedizin Berlin, corporate member of Freie Universität

Berlin, Humboldt-Universität zu Berlin, and Berlin Institute of Health,

Department of Anesthesiology and Surgical Intensive Care, Berlin, Germany
}

RCT, the effect of standardized rehabilitation therapy in patients with acute respiratory failure leads to functional results at 6 months after hospital discharge [5]. [6]. And the just published study of an early mobility program started within $48 \mathrm{~h}$ confirmed improvement in function and increased functional independence [6]. In contrast, studies starting mobilization later had no beneficial effect [2].

Another current meta-analysis using different definitions was able to show an effect of early mobilization [7]. Finally, Ding et al. showed in their network metaanalysis that initiation of mobilization within $48-72 \mathrm{~h}$ in mechanical ventilation patients may be optimal to improve intensive care unit-acquired weakness [8].

In conclusion, as timing seems crucial for patientcentered outcomes, early mobilization should be consistently defined as mobilization within $72 \mathrm{~h}$ of ICU admission.

\section{Acknowledgements Not applicable}

\section{Authors' contributions}

SJS designed the work, and KFK wrote the first draft. Both authors revised the manuscript and read and approved the final manuscript. 


\section{Funding}

Not applicable

\section{Availability of data and materials \\ Not applicable}

Ethics approval and consent to participate

Not applicable

\section{Consent for publication}

Not applicable

\section{Competing interests}

The authors declare that they have no competing interests.

Received: 13 January 2020 Accepted: 27 January 2020

Published online: 12 March 2020

\section{References}

1. Okada Y, Unoki T, Matsuishi Y, et al. Early versus delayed mobilization for inhospital mortality and health-related quality of life among critically ill patients: a systematic review and meta-analysis. J Intensive Care. 2019;7(1):1-9.

2. Fuest K, Schaller SJ. Recent evidence on early mobilization in critical-ill patients. Curr Opin Anaesthesiol. 2018;31(2):144-50.

3. Bein T, Bischoff M, Bruckner U, et al. S2e guideline: positioning and early mobilisation in prophylaxis or therapy of pulmonary disorders : revision 2015: S2e guideline of the German Society of Anaesthesiology and Intensive Care Medicine (DGAI). Anaesthesist. 2015;64(Suppl 1):1-26.

4. Schweickert WD, Pohlman MC, Pohlman AS, et al. Early physical and occupational therapy in mechanically ventilated, critically ill patients: a randomised controlled trial. Lancet. 2009;373(9678):1874-82

5. Morris PE, Berry MJ, Files DC, et al. Standardized rehabilitation and hospital length of stay among patients with acute respiratory failure: a randomized clinical trial. JAMA. 2016;315(24):2694-702.

6. Schaller SJ, Anstey M, Blobner M, Edrich T, Grabitz SD, Gradwohl-Matis I Heim M, Houle T, Kurth T, Latronico N, Lee J, Meyer MJ, Peponis T, Talmor D, Velmahos GC, Waak K, Walz JM, Zafonte R, Eikermann M. Early, goaldirected mobilisation in the surgical intensive care unit: a randomised controlled trial. Lancet. 2016;388:1377-88.

7. Zhang L, Hu W, Cai Z, et al. Early mobilization of critically ill patients in the intensive care unit: a systematic review and meta-analysis. PLoS One. 2019;14(10):e0223185.

8. Ding N, Zhang Z, Zhang C, et al. What is the optimum time for initiation of early mobilization in mechanically ventilated patients? A network metaanalysis. PLoS One. 2019;14(10):e0223151.

\section{Publisher's Note}

Springer Nature remains neutral with regard to jurisdictional claims in published maps and institutional affiliations. 